\title{
Epithelial cell-derived cytokines: more than just signaling the alarm
}

\author{
Florence Roan, ${ }^{1,2}$ Kazushige Obata-Ninomiya, ${ }^{1}$ and Steven F. Ziegler ${ }^{1,3}$ \\ ${ }^{1}$ Immunology Program, Benaroya Research Institute at Virginia Mason, Seattle, Washington, USA. ${ }^{2}$ Division of Allergy and Infectious Diseases and ${ }^{3}$ Department of Immunology, University of Washington, \\ Seattle, Washington, USA.
}

\begin{abstract}
The epithelial cell-derived cytokines thymic stromal lymphopoietin (TSLP), IL-33, and IL-25 are central regulators of type 2 immunity, which drives a broad array of allergic responses. Often characterized as "alarmins" that are released by the barrier epithelium in response to external insults, these epithelial cell-derived cytokines were initially thought to act only early in allergic inflammation. Indeed, TSLP can condition dendritic cells to initiate type 2 responses, and IL-33 may influence susceptibility to asthma through its role in establishing the immune environment in the perinatal lungs. However, TSLP, IL-33, and IL-25 all regulate a broad spectrum of innate immune cell populations and are particularly potent in eliciting and activating type 2 innate lymphoid cells (ILC2s) that may act throughout allergic inflammation. Recent data suggest that a TSLP/ILC axis may mediate steroid resistance in asthma. Recent identification of memory Th2 cell subsets that are characterized by high receptor expression for TSLP, IL-33, and IL-25 further supports a role for these cytokines in allergic exacerbations. There is therefore growing interest in developing biologics that target TSLP, IL-33, and IL-25. This Review provides an overview of TSLP, IL-33, and IL-25 and the development of blocking antibodies that target these epithelial cellderived cytokines.
\end{abstract}

The epithelial lining of the skin, gut, and lungs has long been known as a protective barrier against infection and physical or chemical injury. As the primary organ that senses the external environment, it is now clear that the barrier epithelium also functions as a key sensor and integrator of environmental cues. Allergic diseases encompass a wide breadth of pathological immune responses to otherwise innocuous antigens that are encountered at barrier sites of the body. These responses, called type 2 immune responses, also provide protection against helminth infections. In allergic diseases, type 2 inflammation can drive atopic dermatitis (AD) in the skin; food allergies and eosinophilic esophagitis (EoE) in the gastrointestinal tract; or asthma, allergic rhinitis, and chronic rhinosinusitis within the respiratory system. The prototypical type 2 response is characterized by induction of Th2 cells; B cell production of IgE; activation of specific innate cell populations such as type 2 innate lymphoid cells (ILC2s), eosinophils, mast cells, and basophils; and production of type 2 cytokines such as IL-4, IL-5, IL-9, and IL-13 by innate and adaptive immune cells. The itch response, mucus production, and bronchoconstriction may also be components of the type 2 allergic response.

Regulatory T cells (Tregs), which are important in maintaining immune homeostasis, also regulate type 2 immunity at barrier surfaces. Mice that lacked the CNS1 gene regulatory region at the FOXP3 locus, which is required for peripheral induction of Tregs, spontaneously developed type 2 inflammation within the gastrointestinal tract and lungs (1). Mice whose Tregs lacked expression

Conflict of interest: The authors have declared that no conflict of interest exists. Copyright: (c) 2019 American Society for Clinical Investigation Reference information: / Clin Invest. 2019;129(4):1441-1451. https://doi.org/10.1172/JCI124606. of the transcription factor ROR $\alpha$ exhibited exaggerated type 2 skin inflammation in models of AD (2). This exaggerated inflammation in ROR $\alpha$-deficient Tregs may have been in part due to decreased expression of death receptor 3 (DR3; also known as TNF receptor superfamily member 25 , or TNFRSF25) on Tregs. DR3 on Tregs can bind the ligand TL1A (also known as TNF superfamily member 15, or TNFSF15) and may sequester TL1A to restrain TL1A-driven inflammation by Th2 cells and ILC2s. Additional data also suggest that Tregs can regulate ILC2 function through ICOS-ICOSL interactions and production of IL-10 and TGF- $\beta$ (3).

In epithelial regulation of allergic type 2 responses, three cytokines - thymic stromal lymphopoietin (TSLP), IL-33, and IL-25 have emerged as critical mediators of type 2 inflammation. These cytokines alert the immune system to external insults and regulate tissue restoration and repair after injury. While our understanding of how these cytokines function initially focused on their roles early in type 2 responses, emerging data suggest that these three cytokines provide important tissue-specific signals to both innate and adaptive cell populations throughout type 2 inflammation. TSLP, IL-33, and IL-25 may therefore be important mediators of inflammation during allergic disease exacerbations and may prove to be key targets for therapeutic intervention even after disease is well established. This Review provides an overview of the regulation and function of TSLP, IL-33, and IL-25. We also discuss the current status of the development of treatments that target TSLP, IL-33, or IL-25.

\section{TSLP}

TSLP is a member of the IL-2 family of cytokines that was initially identified as a pre-B cell growth factor (4). Epithelial cells in the lungs, skin, and gastrointestinal tract are thought to be the primary source of TSLP during both homeostatic and inflammatory condi- 
tions, although dendritic cells (DCs), basophils, and mast cells can also express TSLP (5-9). TSLP expression and release from epithelial cells is increased in response to a broad array of stimuli, including mechanical injury, infection, inflammatory cytokines, and proteases such as trypsin and papain $(6,10,11)$. Two main isoforms of TSLP have been described in mice, but the functional consequence of these variants is unknown. In humans, a short isoform appears to be expressed in basal conditions, whereas a longer isoform is induced by inflammatory stimuli (12). Cleavage of human TSLP by serine proteases may also regulate TSLP protein levels or function, although it is unclear whether a similar regulatory mechanism exists in mice $(13,14)$. TSLP genetic variants and high levels of TSLP expression have been linked to atopic diseases such as $\mathrm{AD}$, asthma, allergic rhinoconjunctivitis, and EoE (15). TSLP overexpression has also been reported in Netherton syndrome, a genetic disease caused by mutations in SPINK5 that manifests in type 2 inflammation at multiple sites (16), and in some nonatopic pulmonary diseases such as chronic obstructive pulmonary disease (9).

TSLP is a distant paralog of IL-7 and shares a common receptor subunit, IL-7R $\alpha$, with IL-7. TSLP binds the TSLP receptor (TSL$\mathrm{PR}$ ) that is coupled with IL-7R $\alpha$ to activate downstream pathways (17); TSLP-mediated signaling has been studied primarily in DCs and $\mathrm{T}$ lymphocytes, in which signaling occurred primarily through JAK/STAT pathways (18-20). A number of non-hematopoietic cell populations have been shown to express TSLPR and to be responsive to TSLP. Although the implications in allergic inflammation are not known, the barrier epithelium can respond to TSLP, and TSLP mediated recovery from colonic inflammation in a mouse model of colitis by inducing intestinal epithelial production of secretory leukocyte peptidase inhibitor (SLPI) (21). A growing body of literature also suggests that TSLP can activate a subset of sensory neurons to drive the itch response in allergic diseases such as $\operatorname{AD}(22,23)$.

TSLPR is broadly expressed within hematopoietic cell populations (24). The highest expression is seen on specific myeloid DC populations (25-27), which have been shown to be important TSLP-responsive populations in both humans and mice. TSLP-stimulated DCs upregulated the costimulatory molecules CD40, CD80, CD86, and OX40L $(28,29)$. When cocultured with TSLP-conditioned DCs, naive syngeneic T cells proliferated but did not differentiate; naive allogeneic $\mathrm{T}$ cells cocultured with TSLP-conditioned DCs acquired an inflammatory Th2-like phenotype with production of IL-4, IL-5, IL-13, and TNF- $\alpha$ but not IL-10 (30). TSLP-conditioned DCs could also support the maintenance of Th2 effector memory cells and promotion of IgA2 class switching in the intestines $(31,32)$. The actions of TSLP directly on $\mathrm{T}$ cells can also promote type 2 responses. TSLP signaling on naive $\mathrm{T}$ cells in the presence of TCR stimulation promoted proliferation and Th2 differentiation through induction of IL-4 gene transcription (33-35). Recent data demonstrated that TSLP could directly promote Th2 differentiation and type 2 cytokine expression from naive T cells in vitro, even in the absence of IL-4 (18). In vivo, in an OVA/alum immunization model using antigen-specific $\mathrm{T}$ cells, it was noted that $\mathrm{T}$ cells lacking TSLPR acquired an effector phenotype after immunization but were defective in the ability to generate Th2 memory (36). In a variety of models of allergic disease, TSLP can regulate induction of Th2 cells and Th9 cells, likely through its effects on DCs and T cells $(28,29,33-35,37-40)$. TSLP can also act directly on Tregs in the skin and has been implicated in regulating the generation of Tregs in the thymus and microbiota-driven expansion and maintenance of Helios-negative Tregs in the gut (41-43). The impact of TSLP regulation of Tregs in allergic inflammation remains unclear.

In addition to DCs, basophils and innate lymphoid cells (ILCs) have also emerged as important innate effector cell populations downstream of TSLP. In mouse models, a TSLP/basophil axis has been shown to be important in experimental EoE and food allergy (44-46), and TSLP drove basophil hematopoiesis independent of IL-3 (47). In some models, TSLP-driven allergic inflammation was mediated by ILCs $(48,49)$. Given the importance of respiratory virus infections in driving asthma exacerbations, it is interesting to note that respiratory viruses can induce TSLP expression, and type I interferons induced during the antiviral response can play a counterregulatory role by modulating ILC2 activity (50-52). Several recent publications have now suggested that a TSLP/ILC axis may play a pivotal role in steroid-resistant allergic airway inflammation. TSLP signaling induced expression of the antiapoptotic protein BCL-XL in ILC2s and prevented corticosteroid-induced apoptosis of ILC2s in vitro (53). In vivo, TSLP signaling was not required to drive inflammation following OVA/IL-33 administration, but lack of TSLP signaling greatly enhanced the ability of dexamethasone to suppress inflammation in this model of allergic lung inflammation (53). Data from human subjects suggest a similar and important role for a TSLP/ILC axis, since TSLP could also mediate resistance to corticosteroids in ILC2s from human PBMCs and bronchoalveolar lavage (BAL) fluid. Furthermore, TSLP levels in the BAL fluid from asthmatic patients were inversely correlated with dexamethasone-mediated inhibition of IL-5 production from BAL fluid ILC2s (54). Since steroid therapy is a cornerstone for many allergic and inflammatory diseases, further study of the TSLP/ILC axis is certainly warranted to determine whether similar mechanisms regulate inflammation at other tissue sites.

\section{IL-33}

IL-33 is an IL-1 family cytokine that may exert a broad spectrum of effects extending from early immune development to atopic disease exacerbations. IL-33 was initially named "nuclear factor in high endothelial venules" (NF-HEV) based on its high expression in the nucleus of HEVs (55). The link between IL-33 and type 2 immune responses was established when IL-33 was identified as the ligand for suppression of tumorigenicity 2 (ST2; sometimes referred to as IL-1RL1, T1, or IL-33R) (56), which had been characterized previously as an orphan receptor important in type 2 responses in the lungs $(57,58)$. Genetic studies have reproducibly demonstrated significant associations between IL33 and ILIRL1 genetic variants and asthma in humans (59-66). Genetic variants in $I L 1 R L 1$ are also associated with AD risk (67), and genetic variants in the IL33 and IL1RL1 loci are associated with EoE risk $(68,69)$.

Epithelial cells at barrier surfaces and endothelial cells, both of which express IL-33 constitutively in the nucleus, are thought to be the primary sources of IL-33 during homeostatic and inflammatory conditions $(67,70,71)$. A variety of other hematopoietic and non-hematopoietic cell types have also been reported to express IL-33 under basal conditions or after treatment with inflammatory 
stimuli $(67,70,72-79)$. In specific contexts, cell types other than epithelial and endothelial cells may serve as important sources for IL-33. For example, mast cell-derived IL-33 may be important in experimental autoimmune encephalitis and in intestinal helminth infections $(80,81)$

Like the activity of other IL-1 family cytokines, the activity of IL-33 is regulated both by its localization within the cell and by proteolytic cleavage. IL-33 contains an N-terminal chromatin-binding motif and a predicted nuclear localization sequence. Although some studies suggest a role for IL-33 in transcriptional regulation (82), the intranuclear localization of IL-33 in most cell types is thought to be important in sequestering this cytokine to prevent inappropriate release (83). Transgenic mice that expressed a form of IL-33 that lacked the nuclear localization signal died of systemic inflammation (84). Although IL-33 lacks a signal sequence required for conventional secretory pathways, it can be released as an "alarmin" in response to cellular injury or stress $(85,86)$. Full-length IL-33 appears to be biologically active, but proteolytic cleavage of IL-33 at various sites can modulate its activity. Mast cell and neutrophil proteases can cleave and further activate IL-33 (87-89). Certain allergens also contain proteases that can cleave and further activate IL-33 (90). In contrast, cleavage of IL-33 by caspase-1, -3 , or -7 or oxidation of IL-33 results in inactivation $(91,92)$. Splice variants of IL-33 also exist, although how these different isoforms differ in activity and regulation is not fully understood (93-95).

IL-33 binds a heteromeric receptor consisting of ST2 and its coreceptor IL-1 receptor accessory protein (IL-1RAcP). Formation of the IL-33/ST2/IL-1RAcP complex results in recruitment of MyD88 and IL-1R-associated kinase (IRAK) to activate a variety of downstream signaling pathways (96). A soluble variant of ST2 (sST2) that lacks the transmembrane domain appears to function as a decoy receptor to negatively regulate IL-33/ST2 signaling $(97,98)$. ST2 is constitutively expressed on several immune cell types, including mast cells, ILC2s, Th2 cells, and a subset of Tregs, and can be induced on many other immune subsets; as a consequence, IL-33 can also directly activate and induce cytokine production from a broad number of cell types $(79,99-109)$. Recently, leukotrienes and IL-33 have been shown to act together in a signaling circuit that may be an important amplifier of inflammation in allergic disease exacerbations. Signaling through the leukotriene receptor CysLT2R on alveolar cells drove the production of IL-33, which acted on $\mathrm{T}$ cells to upregulate $\mathrm{T}$ cell expression of the leukotriene receptor CysLT1R $(110,111)$. Some non-hematopoietic cell types are also IL-33-responsive. ST2 expressed on human airway epithelium may mediate inflammatory cytokine production from the bronchial epithelium $(112,113)$; and, like TSLP, IL-33 has also been shown to mediate the itch response through activation of sensory neurons (114).

IL-33 is a particularly potent activator of ILC2s, which produce type 2 cytokines such as IL-13 and IL-5 and upregulate surface OX4OL and PD-L1 in response to IL-33 (107, 115-118). In mice, systemic IL-33 also mobilized ILC2 precursors from the bone marrow (119). In a papain-driven model of allergic lung inflammation, IL-33-mediated activation of ILC2s was important in inducing Th2 cells in the draining lymph nodes and in promoting memory Th2 responses in the lungs $(120,121)$. Memory Th2 cells, which express ST2 at higher levels than effector Th2 cells, are another important effector cell type responsive to IL-33 $(122,123)$. In vivo, after house dust mite (HDM) exposure, IL-33 signaling on memory Th2 cells induced amphiregulin production, which then drove osteopontin production by eosinophils $(123,124)$. It is interesting to note that EGFR, the receptor for amphiregulin, can form a complex with ST2, and EGFR was required for IL-33-induced IL-13 production during helminth infections in mice (125). In helminth infection, an $\mathrm{ST} 2^{+}$subset of memory Th 2 cells was required to drive production of major basic protein (MBP) by eosinophils after infection (123, 124). While ILC2 and pathogenic memory Th2 cell populations both express high levels of ST2 and share transcriptional and epigenetic profiles (126), Th2 cells but not ILC2s express DUSP10, a phosphatase that can negatively regulate IL-33-mediated cytokine production (127). It is now also clear that IL-33 can promote the induction and function of Tregs in a variety of settings (103, 128-130). The implications of this role for IL-33 in suppressing inflammation in allergic disease are not fully understood, though IL-33 was shown to negatively regulate allergic inflammation by inducing Tregs via an IL-33/mast cell/IL-2 axis (131).

In the developing lungs in mice, IL-33 has been shown to have an important role in establishing the pulmonary immune environment that influences the risk and development of allergic lung inflammation later in life. These studies have shown direct links between perturbations in IL-33/ST2 signaling in the perinatal period and subsequent type 2 responses to allergen. Following a perinatal increase in IL-33 expression in the lungs, pulmonary ILC2 frequencies increased (132-134). ILC2s mediated eosinophil accumulation in the lungs during the neonatal period and were the primary source of IL-13 in the neonatal lungs that drove the phenotypic polarization of pulmonary macrophages. Tissue insults such as hyperoxia that occur during the perinatal period can increase IL-33 expression and mobilize ILC2s, leading to increased susceptibility to asthma later in life (135). IL-33 also drove a lung-specific transcriptional program in basophils in the developing lungs, since the gene expression profile of lung basophils from ST2-deficient neonatal mice was more similar to that of wild-type circulating basophils than to that of wild-type lung basophils (136). Thus, IL-33 signaling impacts all stages of allergy starting even from the establishment of the immune environment in the perinatal lungs.

\section{IL-25}

IL-25 (sometimes referred to as IL-17E) is a member of the IL-17 cytokine family, although the functions of IL-25 have been shown to be quite distinct from those of other IL-17 cytokine family members given IL-25's ability to amplify type 2 inflammation at multiple tissue sites (137-140). Blockade of IL-25 signaling can attenuate allergic inflammation in a variety of mouse models (141-143). Although initial reports described IL-25 as a Th2 cell-derived cytokine (137), epithelial cells, alveolar macrophages, mast cells, basophils, and eosinophils have now also been reported as potential sources of IL-25 (141, 144-148). IL-25 was constitutively expressed by epithelial cells of the skin and lungs in subjects with asthma or atopic disease, and expression of IL-25 was higher in the skin and lungs of subjects with asthma and atopic disease than in the skin and lungs of control subjects $(147,148)$. In subjects with chronic 
A Establishing the perinatal immune environment in the lungs

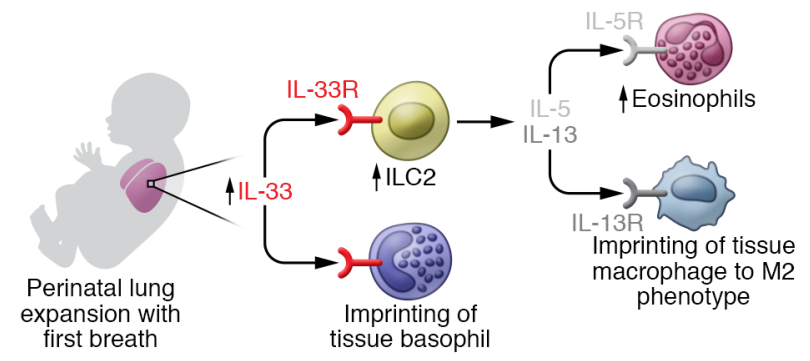

B Allergen sensitization (DC conditioning) and Th2 cell development

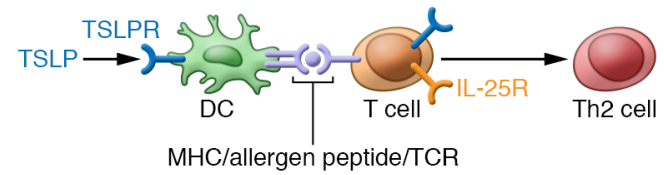

C Eliciting or activating innate immune cells, especially ILC2S

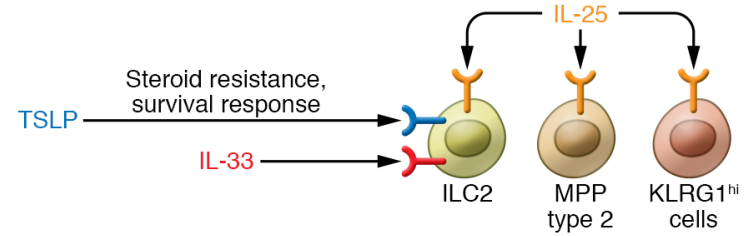

D Stimulating the itch response

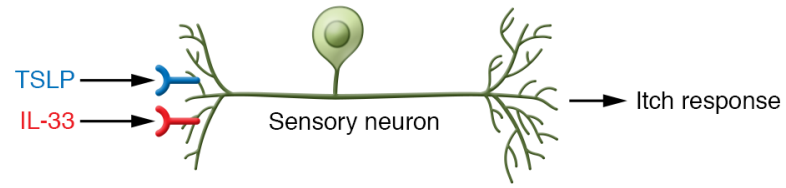

E Promoting memory Th2 cell responses

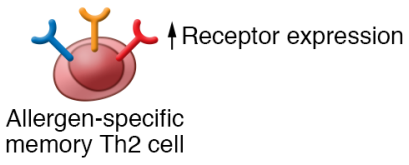

Figure 1. TSLP, IL-33, and IL-25 regulate a diversity of responses in type 2 immunity. (A) IL-33 release in the lungs at birth helps establish the pulmonary immune environment, which can influence asthma risk and development later in life. (B) TSLP acts directly on DCs to drive Th2 cell development; IL-25, along with IL-4, can also drive Th2 cell differentiation. (c) TSLP, IL-33, and IL-25 act on a broad array of innate immune cells and are particularly important in eliciting and activating ILC2s; IL-25 can also elicit MPP type 2 cells and IL-17+ KLRG $^{\text {hi }}$ cells. (D) TSLP and IL-33 can act on sensory neurons to stimulate the itch response. (E) TSLP, IL-33, and IL-25 can promote adaptive type 2 responses through subsets of memory Th2 cells that are characterized by high receptor expression for TSLP, IL-33, and IL-25.

rhinosinusitis, solitary chemosensory cells (SCCs) appeared to be the primary source of IL-25 within the sinonasal epithelium, and SCCs were expanded in nasal polyp tissue compared with adjacent turbinate epithelium (149). Within the lungs and intestines in mice, IL-25 expression was restricted to tuft cells, a rare type of chemosensory epithelial cell (150-152). IL-25 expression by tuft cells was further induced by succinate or helminth-derived products and mediated intestinal epithelial remodeling in response to colonizing protozoa, which protected against helminth infections $(150,153,154)$. Few data exist on whether IL-25 expression and function are regulated by splicing or proteolytic cleavage; however, IL-25 has been reported to be a substrate for cleavage by matrix metalloproteinase 7 (MMP-7) (155).

IL-25 binds IL-17RB, and along with IL-17RA recruits the adapter protein Akt1 to activate downstream signaling pathways (138, 156-159). Cellular targets of IL-25 include T cells, ILC2s, specific myeloid populations, and invariant NKT cells, as well as non-hematopoietic cell populations such as fibroblasts, epithelial cells, endothelial cells, and mesenchymal cells (118, 137, 146, 147, 160-166). An IL-25-responsive, steroid-resistant myeloid population was a critical mediator of disease in a model of cockroach allergen-driven chronic allergic lung inflammation (167). In addition to acting on ILC2s, which are activated or elicited by TSLP and IL-33, IL-25 may also induce some functionally and phenotypically distinct ILC populations: multipotent progenitor (MPP) type 2 cells and IL-17-producing KLRG ${ }^{\text {hi }}$ cells $(162,165)$. A subset of NKT cells has also been shown to produce type 2 cytokines in response to IL-25 and could drive airway hyperresponsiveness in an OVA/alum model of allergic airway inflammation (164). As with TSLP and IL-33, T cells also appear to be important target cells in IL-25-mediated inflammation. Ex vivo analyses of human peripheral blood demonstrated high expression of IL-17RB transcript and protein in memory Th2 cells that was greatly enhanced by coculture with TSLP-conditioned DCs (147). Augmentation of Th2 differentiation and function by IL-25 appeared to be dependent on IL-4, since naive T cells lacking IL-4 or antibody blockade of IL- 4 abrogated the ability of IL- 25 to induce Th2 differentiation in vitro (146). IL-25 does not appear to drive Th9 differentiation, but Th9 cells expressed IL-17RB and increased IL-9 production in response to IL-25 (168). Under homeostatic conditions, IL-25 can play an important role in limiting IL-17 expression within the gut. Intestinal commensal microbiota drove expression of IL-25 from the epithelium, which limited IL-23 expression and Th17 cell expansion in the large intestines and limited IL-22 production from ROR $\gamma \mathrm{t}^{+}$ILCs (ILC3s) in the small intestines $(169,170)$. Although the implications in allergy are unclear, recent data also demonstrated an important role for IL-25 in driving keratinocyte proliferation and skin inflammation in an IL-17-dependent imiquimod-induced psoriasis model (171). Additional data linking IL-25 to Th17-type responses come from a hapten-mediated model of contact hypersensitivity (CHS). CHS mediated by transferred Th2 cells was comparable in wild-type and IL-25-deficient mice, yet transferred Th17 cells could drive inflammation in wild-type but not IL-25-deficient mice (172).

\section{TSLP, IL-33, and IL-25: interplay and tissue-specific roles}

Although TSLP, IL-33, and IL-25 can all promote type 2 inflammation through their effects on a broad array of cell populations (Figure 1 and Table 1), the downstream effector profiles can be distinct in response to these three cytokines (173), and cells may express different levels of receptors for TSLP, IL-33, or IL-25 in a tissue-dependent manner (174). Studies in mouse models have demonstrated 
Table 1. Cellular sources and targets of TSLP, IL-33, and IL-25

TSLP

IL-33

IL-25

\begin{tabular}{|c|c|c|c|}
\hline \multicolumn{4}{|l|}{ Sources } \\
\hline \multirow[t]{7}{*}{ Non-hematopoietic } & Epithelial cells & Epithelial cells & $\begin{array}{l}\text { Epithelial cells (esp. tuft cells, } \\
\text { solitary chemosensory cells) }\end{array}$ \\
\hline & Stromal cells & Endothelial cells & \\
\hline & & $\begin{array}{c}\text { Fibroblastic reticular cells, } \\
\text { fibroblasts, fibroblast-like cells, } \\
\text { myofibroblasts }\end{array}$ & \\
\hline & & Adipocytes & \\
\hline & & Smooth muscle cells & \\
\hline & & Glial cells & \\
\hline & & Hepatocytes & \\
\hline \multirow[t]{5}{*}{ Hematopoietic } & Dendritic cells & Various myeloid cell types & Alveolar macrophages \\
\hline & Mast cells & Mast cells & Mast cells \\
\hline & Basophils & Platelets, megakaryocytes & Basophils \\
\hline & & & Eosinophils \\
\hline & & & Th2 cells \\
\hline \multicolumn{4}{|l|}{ Targets } \\
\hline \multirow[t]{6}{*}{ Non-hematopoietic } & Epithelial cells & Epithelial cells & Epithelial cells \\
\hline & Sensory neurons & Endothelial cells & Endothelial cells \\
\hline & & Stromal cells, fibroblasts & Fibroblasts \\
\hline & & Sensory neurons & Mesenchymal cells \\
\hline & & Glial cells & \\
\hline & & Cardiomyocytes & \\
\hline \multirow[t]{14}{*}{ Hematopoietic } & Type 2 ILCs (ILC2s) & Type 2 ILCs (ILC2s) & Type 2 ILCs \\
\hline & $\mathrm{CD}^{+} \mathrm{T}$ cells & $\mathrm{CD4}^{+} \mathrm{T}$ cells & (ILC2s, MPP type 2, IL-17+KLLRG1'i) \\
\hline & (Th2, Th9, naive T cells) & (Th2, Th1, Th17) & $\mathrm{CD}^{+} \mathrm{T}$ cells (Th2, Th9, naive T cells) \\
\hline & Tregs & Tregs & iNKT cells \\
\hline & $\mathrm{CD}^{+} \mathrm{T}$ cells & $\mathrm{CDB}^{+} \mathrm{T}$ cells & Specific myeloid populations \\
\hline & NKT cells & NK cells & \\
\hline & B cells & iNKT cells & \\
\hline & Mast cells & B cells & \\
\hline & Basophils & Mast cells & \\
\hline & Eosinophils & Basophils & \\
\hline & Dendritic cells & Eosinophils & \\
\hline & Monocytes, macrophages & Dendritic cells & \\
\hline & & Macrophages & \\
\hline & & Neutrophils & \\
\hline
\end{tabular}

tion or after HDM challenge despite the fact that lymph node priming of adaptive type 2 immunity remained intact (126).

The recent identification of subsets of memory Th2 cells in humans and mice that are characterized by high expression of receptors for TSLP, IL-33, and IL-25 supports a role for these three cytokines in regulating adaptive immune responses in allergy. These Th2 subpopulations are enriched at affected sites in EoE and AD and constitute a higher frequency of circulating Th2 cells in subjects with seasonal allergies than in control subjects $(176,177)$. It is interesting to speculate whether the increased responsiveness of these memory Th2 cells to TSLP, IL-33, and IL-25 may be important in mediating the allergic phenotype, since the mere presence or absence of allergen-specific $\mathrm{T}$ cells does not appear to distinguish allergic from nonallergic subjects $(178,179)$. Additional research is required to assess whether each of these epithelial cell-derived cytokines is uniformly required across a spectrum of human allergic diseases or whether patterns of expression of these cytokines may distinguish distinct allergic endotypes or phenotypes.

\section{Other epithelial cytokines}

While TSLP, IL-33, and IL-25 have been highlighted as important epithelial cellderived cytokines in allergy because of their potent ability to drive type 2 responses, it is important to note that numerous other cytokines produced by the barrier epithelium also have key roles in regulating allergic diseases. A growing body of literature implicates granulocyte-macrophage colony-stimulating factor (GM-CSF) in the regulation of allergic responses. GM-CSF was able to serve as an adjuvant to drive type 2 lung inflammation in response to

differential requirements for TSLP, IL-33, and IL-25. In some models, the allergen dose or mouse genetic background can influence the requirements for these epithelial cell-derived cytokines. At low doses of HDM, blockade of either IL-33 or GM-CSF but not TSLP attenuated HDM-driven allergic lung inflammation, but inflammation driven by high-dose HDM was attenuated in the absence of TSLP signaling (175). C57BL/6 mice that lacked TSLP signaling had greatly attenuated skin inflammation after topical application of the vitamin D analog MC903 (48); yet, in BALB/c mice, IL-25 may play a more important role than TSLP, since MC903-driven inflammation was decreased to a greater extent in mice that lacked the IL-25 receptor IL-17RB than in mice that lacked either TSLPR or ST2 (117). Some studies suggest a tissue-specific role for TSLP, IL-33, and IL-25, as mice lacking TSLP, IL-33, and IL-25 signaling had impaired type 2 immune responses in tissue in helminth infec- low-dose HDM or OVA alone $(180,181)$, and blockade or loss of GM-CSF signaling attenuated allergic inflammation in a variety of mouse models $(175,182-185)$. Studies examining the role of GM-CSF in allergic lung inflammation suggest a primary role for GM-CSF during allergic sensitization (184). IL-1 $\alpha$ may also be important during sensitization but not challenge since neutralization of IL- $1 \alpha$ but not IL-1 $\beta$ during sensitization reduced type 2 inflammation in an HDM-driven asthma model, whereas inflammation was not affected by blockade of IL-1 $\alpha$ or IL-1 $\beta$ during the challenge phase in this model (175). In fact, TLR4-induced IL-1 $\alpha$ from bronchial epithelial cells provided an important autocrine signal for GM-CSF and IL-33 release, suggesting that IL- $1 \alpha$ may be one of the earliest triggers of type 2 immunity in the lungs. Studies of $\mathrm{AD}$ also suggest that keratinocyte release of IL-1 $\alpha$ can drive chronic skin inflammation (186). 


\section{Table 2. Clinical trials of drugs targeting TSLP or IL-33/ST2 ${ }^{A}$}

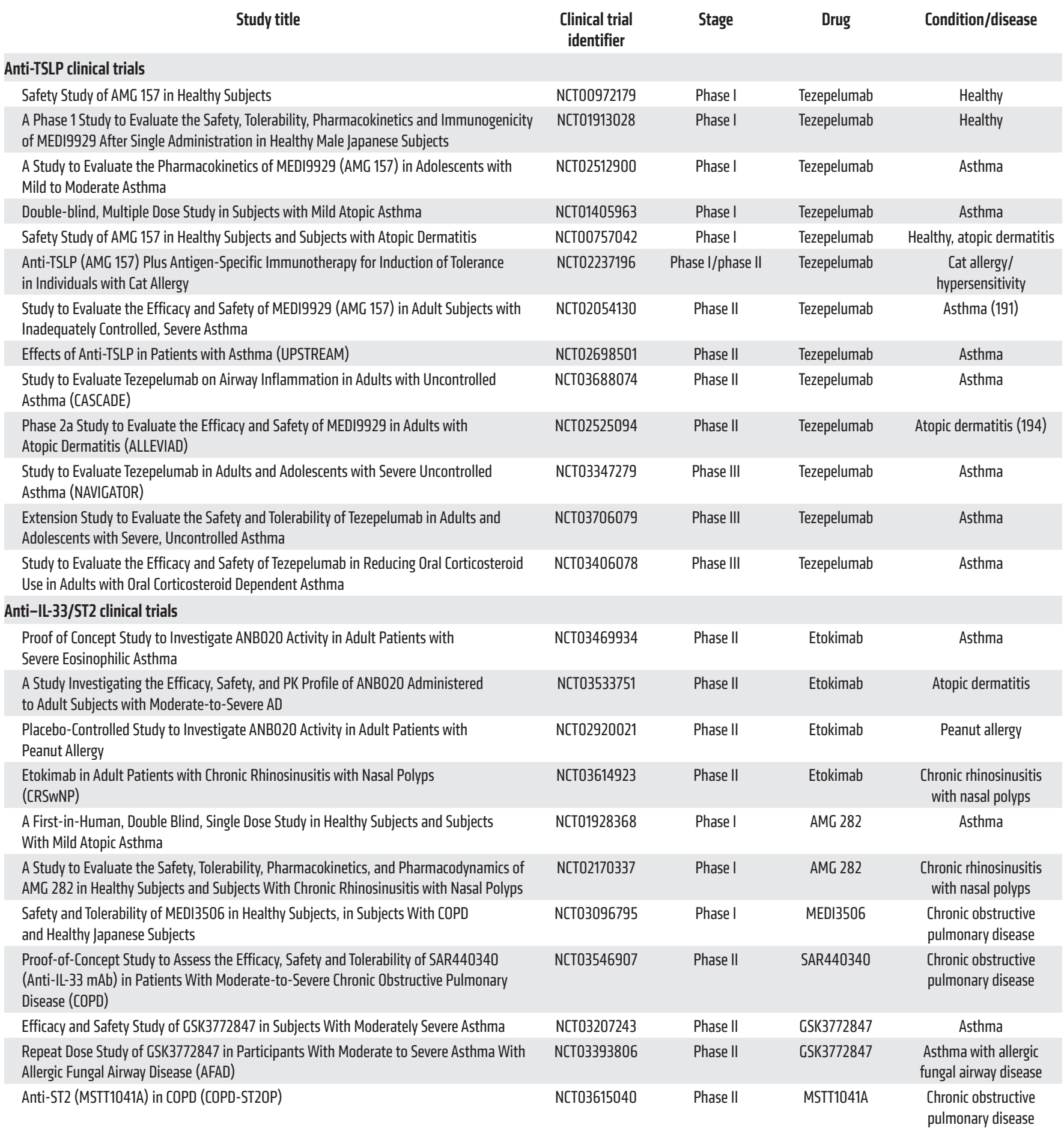

AFrom ClinicalTrials.gov, accessed December 5, 2018. Includes trials that are completed or recruiting.

Studies have also highlighted a potential role for TGF- $\beta$, and, in particular, epithelial cell-derived TGF- $\beta$, in the pathogenesis of asthma. A critical role for TGF- $\beta$ in mediating tolerance through Treg induction has been well established; thus, some studies have investigated TGF- $\beta$ in allergy as a potential mode of therapy $(187,188)$. However, loss of TGF- $\beta$ expression specifically from the bronchial epithelium reduced ILC2 accumulation and IL-13 production in the lungs following HDM administration (189). The association of SNPs in the promoter and coding regions of the TGFB1 gene with asthma susceptibility and degree of atopy further supports an important role for TGF- $\beta$ in allergic disease (190). Given the opposing roles that have been described for 
TGF- $\beta$ in suppressing or promoting allergic inflammation, further study is needed to better understand how TGF- $\beta$ regulates type 2 immunity at barrier tissue sites.

\section{Development of biologics against epithelial cytokines}

Although biological therapies directed against IgE and some effector cytokines have been developed, studies in mouse models suggest that epithelial cell-derived cytokines such as TSLP, IL-33, and IL-25 may regulate allergic responses more broadly and through more diverse pathways than IgE or type 2 effector cytokines such as IL-4, IL-13, or IL-5. There is therefore growing interest in developing therapeutics to target TSLP, IL-33, and IL-25. Antibodies directed against IL-25 are under development but have not yet entered clinical trials. One antibody directed against TSLP and several antibodies that block IL-33/ST2 signaling are under development (Table 2). Therapeutics directed against TSLP and IL-33 have not yet been approved by the FDA, but several trials that have been conducted suggest that these antibodies may be both safe and effective in a variety of atopic diseases.

TSLP signaling blockade. Tezepelumab (AMG 157/MEDI9929) is a human IgG2 monoclonal antibody that binds human TSLP and prevents the binding of TSLP with TSLPR. Tezepelumab was effective in reducing rates of asthma exacerbations in patients with moderate to severe disease requiring long-acting $\beta$-agonists and medium to high doses of inhaled glucocorticoids (191). A study of responses to allergen challenge in patients with mild allergic asthma suggested that tezepelumab affects both early and late asthmatic responses to allergen exposure (192). Treatment with tezepelumab did not affect total IgE levels in patients with mild asthma but did decrease blood eosinophil counts compared with those of placebo-treated control subjects. Allergen-induced bronchoconstriction after allergen challenge was also attenuated in tezepelumab-treated patients compared with controls. Studies are currently ongoing to evaluate the efficacy of tezepelumab as adjunctive therapy to immunotherapy in inducing long-term tolerance to cat allergen (193). ALLEVIAD, a phase IIa study of safety and efficacy of tezepelumab in adults with $\mathrm{AD}$, has also been completed, and although higher numbers of subjects treated with tezepelumab reached an improvement of $50 \%$ or more in the Eczema Area Severity Index (EASI-50), the study did not reach the level of significance in this primary endpoint (194). It will be particularly interesting to establish whether blockade of TSLP may be effective in steroid-resistant asthma given recent studies suggesting a central role for TSLP and ILCs in steroid resistance in mouse models of allergic inflammation.

IL-33 signaling blockade. Etokimab (ANBO20) is a humanized anti-IL-33 IgG1 antibody generated by AnaptysBio that is being evaluated in a number of studies in the treatment of $\mathrm{AD}$, eosinophilic asthma, peanut allergy, and chronic rhinosinusitis with nasal polyps (195). In vitro analyses demonstrated high-affinity binding to IL-33 and inhibition of IL-33 activity on primary human cells. Phase I and phase IIa trials of etokimab have been completed. Etokimab demonstrated a favorable safety profile, and a single dose of etokimab suppressed IL-33 function for 85 days based on ex vivo assays. In adult subjects with $\mathrm{AD}$ that was inadequately controlled with topical corticosteroids, single dosing was also able to achieve an improvement of $50 \%$ or more in the EASI-50 eczema grading index (196). Interim analyses of a phase IIa study of etokimab in adults with severe eosinophilic asthma demonstrated improvements in forced expiratory volume (FEV1) at day 2 in etokimab-treated patients over patients receiving placebo, and differences in FEV1 measurements between etokimab-treated and placebo-treated patients remained significant at day 64 (197). Improvements in lung function also correlated with reductions in blood eosinophil numbers. Positive responses have also been reported in interim analyses of a phase IIa trial of etokimab in adult peanut allergy patients with a clinical history of anaphylaxis (198).

\section{Conclusions}

Substantial progress has been made in understanding the mechanisms that underlie the development and progression of allergic diseases. The regulation of barrier tissue immune homeostasis by TSLP, IL-33, and IL-25 affects susceptibility to allergic disease development but also modulates the function of cell populations such as memory Th2 cells and ILCs that drive allergic disease exacerbations. Thus, biologics directed against these epithelial cell-derived cytokines may be effective across a broad spectrum of allergic diseases. Antibodies against IL-25 are still in the early stages of development. The anti-TSLP antibody tezepelumab and the anti-IL-33 antibody etokimab have now shown promising results in a variety of allergic diseases. Ongoing and future studies will help establish whether biologics targeting TSLP, IL-33, or IL-25 can offer safe, effective, and steroid-sparing treatments for allergy.

\section{Acknowledgments}

We thank Kathryn Pothoven for helpful discussions. Support for this work was provided by NIH grants R01AI068731, U19AI125378, and R01AI124220 to SFZ.

Address correspondence to: Steven F. Ziegler, Benaroya Research Institute at Virginia Mason, 1201 Ninth Avenue, Seattle, Washington 98101, USA. Phone: 206.287.5657; Email: sziegler@benaroyaresearch.org.
1. Josefowicz SZ, et al. Extrathymically generated regulatory $\mathrm{T}$ cells control mucosal $\mathrm{TH} 2$ inflammation. Nature. 2012;482(7385):395-399.

2. Malhotra N, et al. ROR $\alpha$-expressing T regulatory cells restrain allergic skin inflammation. Sci Immunol. 2018;3(21):eaao6923.

3. Rigas D, et al. Type 2 innate lymphoid cell suppression by regulatory $\mathrm{T}$ cells attenuates airway hyperreactivity and requires inducible T-cell costimulator-inducible T-cell costimulator ligand interaction. J Allergy Clin Immunol. 2017;139(5):1468-1477.e2.

4. Friend SL, Hosier S, Nelson A, Foxworthe D, Williams DE, Farr A. A thymic stromal cell line supports in vitro development of surface IgM+ $\mathrm{B}$ cells and produces a novel growth factor affecting B and T lineage cells. Exp Hematol. 1994;22(3):321-328.

5. Sokol CL, Barton GM, Farr AG, Medzhitov R. A mechanism for the initiation of allergen-induced Thelper type 2 responses. Nat Immunol. 2008;9(3):310-318.

6. Soumelis V, et al. Human epithelial cells trigger dendritic cell mediated allergic inflammation by 
producing TSLP. Nat Immunol.2002;3(7):673-680.

7. Kashyap M, Rochman Y, Spolski R, Samsel L, Leonard WJ. Thymic stromal lymphopoietin is produced by dendritic cells. J Immunol. 2011;187(3):1207-1211.

8. Zhang Y, Zhou X, Zhou B. DC-derived TSLP promotes Th2 polarization in LPS-primed allergic airway inflammation. Eur JImmunol. 2012;42(7):1735-1743.

9. Ying $S$, et al. Expression and cellular provenance of thymic stromal lymphopoietin and chemokines in patients with severe asthma and chronic obstructive pulmonary disease. JImmunol. 2008;181(4):2790-2798.

10. Kato A Jr., Favoreto S, Avila PC, Schleimer RP. TLR3- and Th2 cytokine-dependent production of thymic stromal lymphopoietin in human airway epithelial cells. JImmunol. 2007;179(2):1080-1087.

11. Allakhverdi $Z$, et al. Thymic stromal lymphopoietin is released by human epithelial cells in response to microbes, trauma, or inflammation and potently activates mast cells. JExp Med. 2007;204(2):253-258.

12. Fornasa G, et al. Dichotomy of short and long thymic stromal lymphopoietin isoforms in inflammatory disorders of the bowel and skin. JAllergy Clin Immunol. 2015;136(2):413-422.

13. Biancheri P, et al. Abnormal thymic stromal lymphopoietin expression in the duodenal mucosa of patients with coeliac disease. Gut. 2016;65(10):1670-1680.

14. Poposki JA, et al. Proprotein convertases generate a highly functional heterodimeric form of thymic stromal lymphopoietin in humans. J Allergy Clin Immunol. 2017;139(5):1559-1567.e8.

15. Cianferoni A, Spergel J. The importance of TSLP in allergic disease and its role as a potential therapeutic target. Expert Rev Clin Immunol. 2014;10(11):1463-1474.

16. Briot A, et al. Kallikrein 5 induces atopic dermatitis-like lesions through PAR2-mediated thymic stromal lymphopoietin expression in Netherton syndrome. JExp Med. 2009;206(5):1135-1147.

17. Pandey A, et al. Cloning of a receptor subunit required for signaling by thymic stromal lymphopoietin. Nat Immunol. 2000;1(1):59-64.

18. Rochman $\mathrm{Y}$, et al. TSLP signaling in $\mathrm{CD} 4^{+} \mathrm{T}$ cells programs a pathogenic $\mathrm{T}$ helper 2 cell state. $S c i$ Signal. 2018;11(521):eaam8858.

19. Bell BD, et al. The transcription factor STAT5 is critical in dendritic cells for the development of TH2 but not TH1 responses. Nat Immunol. 2013;14(4):364-371.

20. Lu N, Wang YH, Wang YH, Arima K, Hanabuchi S, Liu YJ. TSLP and IL-7 use two different mechanisms to regulate human $\mathrm{CD} 4{ }^{+} \mathrm{T}$ cell homeostasis. J Exp Med. 2009;206(10):2111-2119.

21. Reardon C, et al. Thymic stromal lymphopoetin-induced expression of the endogenous inhibitory enzyme SLPI mediates recovery from colonic inflammation. Immunity. 2011;35(2):223-235.

22. Wilson SR, et al. The epithelial cell-derived atopic dermatitis cytokine TSLP activates neurons to induce itch. Cell. 2013;155(2):285-295.

23. Oetjen LK, et al. Sensory neurons co-opt classical immune signaling pathways to mediate chronic itch. Cell. 2017;171(1):217-228.e13.
24. Roan F, Bell BD, Stoklasek TA, Kitajima M, Han $\mathrm{H}$, Ziegler SF. The multiple facets of thymic stromal lymphopoietin (TSLP) during allergic inflammation and beyond. J Leukoc Biol. 2012;91(6):877-886.

25. Reche PA, et al. Human thymic stromal lymphopoietin preferentially stimulates myeloid cells. J Immunol. 2001;167(1):336-343.

26. Kitajima M, Ziegler SF. Cutting edge: Identification of the thymic stromal lymphopoietin-responsive dendritic cell subset critical for initiation of type 2 contact hypersensitivity. J Immunol. 2013;191(10):4903-4907.

27. Ochiai S, et al. CD326(lo)CD103(lo)CD11b(lo) dermal dendritic cells are activated by thymic stromal lymphopoietin during contact sensitization in mice. JImmunol. 2014;193(5):2504-2511.

28. Ito $\mathrm{T}$, et al. TSLP-activated dendritic cells induce an inflammatory T helper type 2 cell response through OX40 ligand. J Exp Med. 2005;202(9):1213-1223.

29. Zhou B, et al. Thymic stromal lymphopoietin as a key initiator of allergic airway inflammation in mice. Nat Immunol. 2005;6(10):1047-1053.

30. Watanabe N, et al. Human thymic stromal lymphopoietin promotes dendritic cell-mediated $\mathrm{CD} 4^{+}$ $\mathrm{T}$ cell homeostatic expansion. Nat Immunol. 2004;5(4):426-434.

31. $\mathrm{He} \mathrm{B}$, et al. Intestinal bacteria trigger $\mathrm{T}$ cell-independent immunoglobulin $\mathrm{A}(2)$ class switching by inducing epithelial-cell secretion of the cytokine APRIL. Immunity. 2007;26(6):812-826.

32. Wang YH, et al. Maintenance and polarization of human $\mathrm{TH} 2$ central memory $\mathrm{T}$ cells by thymic stromal lymphopoietin-activated dendritic cells. Immunity. 2006;24(6):827-838.

33. Omori M, Ziegler S. Induction of IL-4 expression in CD4(+) T cells by thymic stromal lymphopoietin. J Immunol. 2007;178(3):1396-1404.

34. Rochman I, Watanabe N, Arima K, Liu YJ, Leonard WJ. Cutting edge: Direct action of thymic stromal lymphopoietin on activated human CD4 T cells. JImmunol. 2007;178(11):6720-6724.

35. Kitajima M, Lee HC, Nakayama T, Ziegler SF TSLP enhances the function of helper type 2 cells. Eur JImmunol. 2011;41(7):1862-1871.

36. Wang Q, Du J, Zhu J, Yang X, Zhou B. Thymic stromal lymphopoietin signaling in $\mathrm{CD} 4(+) \mathrm{T}$ cells is required for TH2 memory. JAllergy Clin Immunol. 2015;135(3):781-791.e3.

37. He R, Oyoshi MK, Garibyan L, Kumar L, Ziegler SF, Geha RS. TSLP acts on infiltrating effector $\mathrm{T}$ cells to drive allergic skin inflammation. Proc Natl Acad Sci U S A. 2008;105(33):11875-11880.

38. Ebner S, et al. Thymic stromal lymphopoietin converts human epidermal Langerhans cells into antigen-presenting cells that induce proallergic $\mathrm{T}$ cells. J Allergy Clin Immunol. 2007;119(4):982-990.

39. Yao $\mathrm{W}$, et al. Interleukin-9 is required for allergic airway inflammation mediated by the cytokine TSLP. Immunity. 2013;38(2):360-372.

40. Al-Shami A, Spolski R, Kelly J, Keane-Myers A, Leonard WJ. A role for TSLP in the development of inflammation in an asthma model. J Exp Med. 2005;202(6):829-839.

41. Kashiwagi M, et al. Direct control of regulatory T cells by keratinocytes. Nat Immunol. 2017;18(3):334-343.
42. Hanabuchi S, et al. Thymic stromal lymphopoietin-activated plasmacytoid dendritic cells induce the generation of $\mathrm{FOXP}^{+}$regulatory $\mathrm{T}$ cells in human thymus. Jimmunol.2010;184(6):2999-3007.

43. Mosconi I, et al. Intestinal bacteria induce TSLP to promote mutualistic T-cell responses. Mucosal Immunol. 2013;6(6):1157-1167.

44. Noti M, et al. Thymic stromal lymphopoietinelicited basophil responses promote eosinophilic esophagitis. Nat Med. 2013;19(8):1005-1013.

45. Noti M, et al. Exposure to food allergens through inflamed skin promotes intestinal food allergy through the thymic stromal lymphopoietin-basophil axis. JAllergy Clin Immunol. 2014;133(5):1390-1399.e1.

46. Muto $\mathrm{T}$, et al. The role of basophils and proallergic cytokines, TSLP and IL-33, in cutaneously sensitized food allergy. Int Immunol. 2014;26(10):539-549.

47. Siracusa MC, et al. TSLP promotes interleukin-3-independent basophil haematopoiesis and type 2 inflammation. Nature. 2011;477(7363):229-233.

48. Kim BS, et al. TSLP elicits IL-33-independent innate lymphoid cell responses to promote skin inflammation. Sci Transl Med. 2013;5(170):170ra16.

49. Verma M, Liu S, Michalec L, Sripada A, Gorska MM, Alam R. Experimental asthma persists in IL-33 receptor knockout mice because of the emergence of thymic stromal lymphopoietin-driven IL-9+ and IL-13+ type 2 innate lymphoid cell subpopulations. JAllergy Clin Immunol. 2018;142(3):793-803.e8.

50. Stier MT, et al. Respiratory syncytial virus infection activates IL-13-producing group 2 innate lymphoid cells through thymic stromal lymphopoietin. JAllergy Clin Immunol. 2016;138(3):814-824.e11.

51 . Han J, et al. Responsiveness to respiratory syncytial virus in neonates is mediated through thymic stromal lymphopoietin and OX40 ligand. J Allergy Clin Immunol. 2012;130(5):1175-1186.e9.

52. Duerr CU, et al. Type I interferon restricts type 2 immunopathology through the regulation of group 2 innate lymphoid cells. Nat Immunol. 2016;17(1):65-75.

53. Kabata H, et al. Thymic stromal lymphopoietin induces corticosteroid resistance in natural helper cells during airway inflammation. Nat Commun. 2013;4:2675.

54. Liu S, et al. Steroid resistance of airway type 2 innate lymphoid cells from patients with severe asthma: the role of thymic stromal lymphopoietin. J Allergy Clin Immunol. 2018;141(1):257-268.e6.

55. Baekkevold ES, et al. Molecular characterization of NF-HEV, a nuclear factor preferentially expressed in human high endothelial venules. Am J Pathol. 2003;163(1):69-79.

56 . Schmitz J, et al. IL-33, an interleukin-1-like cytokine that signals via the IL-1 receptor-related protein ST2 and induces T helper type 2-associated cytokines. Immunity. 2005;23(5):479-490.

57. Coyle AJ, et al. Crucial role of the interleukin 1 receptor family member $\mathrm{T} 1 / \mathrm{ST} 2$ in $\mathrm{T}$ helper cell type 2-mediated lung mucosal immune responses. J Exp Med.1999;190(7):895-902.

58. Löhning M, et al. T1/ST2 is preferentially expressed on murine Th2 cells, independent of 
interleukin 4, interleukin 5, and interleukin 10 , and important for Th2 effector function. Proc Natl Acad Sci U S A .1998;95(12):6930-6935.

59. Ramasamy A, et al. Genome-wide association studies of asthma in population-based cohorts confirm known and suggested loci and identify an additional association near HLA. PLoS One. 2012;7(9):e44008

60. Moffatt MF, et al. A large-scale, consortium-based genomewide association study of asthma. N Engl J Med. 2010;363(13):1211-1221.

61. Bønnelykke K, et al. A genome-wide association study identifies CDHR3 as a susceptibility locus for early childhood asthma with severe exacerbations. Nat Genet. 2014;46(1):51-55.

62. Grotenboer NS, Ketelaar ME, Koppelman GH, Nawijn MC. Decoding asthma: translating genetic variation in IL33 and IL1RL1 into disease pathophysiology. JAllergy Clin Immunol. 2013;131(3):856-865.

63. Torgerson DG, et al. Meta-analysis of genomewide association studies of asthma in ethnically diverse North American populations. Nat Genet 2011;43(9):887-892.

64. Gudbjartsson DF, et al. Sequence variants affecting eosinophil numbers associate with asthma and myocardial infarction. Nat Genet. 2009;41(3):342-347.

65. Savenije OE, et al. Association of IL33-IL-1 receptor-like 1 (IL1RL1) pathway polymorphisms with wheezing phenotypes and asthma in childhood. JAllergy Clin Immunol. 2014;134(1):170-177.

66. Smith D, et al. A rare IL33 loss-of-function mutation reduces blood eosinophil counts and protects from asthma. PLoS Genet. 2017;13(3):e1006659.

67. Savinko T, et al. IL-33 and ST2 in atopic dermatitis: expression profiles and modulation by triggering factors. J Invest Dermatol. 2012;132(5):1392-1400.

68. Kottyan LC, et al. Genome-wide association analysis of eosinophilic esophagitis provides insight into the tissue specificity of this allergic disease. Nat Genet. 2014;46(8):895-900.

69. Martin LJ, et al. Eosinophilic esophagitis (EoE) genetic susceptibility is mediated by synergistic interactions between EoE-specific and general atopic disease loci. J Allergy Clin Immunol. 2018;141(5):1690-1698.

70. Moussion C, Ortega N, Girard JP. The IL-1-like cytokine IL-33 is constitutively expressed in the nucleus of endothelial cells and epithelial cells in vivo: a novel 'alarmin'? PLoS One. 2008;3(10):e3331.

71. Pichery M, et al. Endogenous IL-33 is highly expressed in mouse epithelial barrier tissues, lymphoid organs, brain, embryos, and inflamed tissues: in situ analysis using a novel Il-33LacZ gene trap reporter strain. JImmunol. 2012;188(7):3488-3495.

72. Meephansan J, Tsuda H, Komine M, Tominaga S, Ohtsuki M. Regulation of IL-33 expression by IFN- $\gamma$ and tumor necrosis factor- $\alpha$ in normal human epidermal keratinocytes. J Invest Dermatol. 2012;132(11):2593-2600.

73. Imai $Y$, et al. Skin-specific expression of IL-33 activates group 2 innate lymphoid cells and elicits atopic dermatitis-like inflammation in mice. Proc
Natl Acad Sci U S A. 2013;110(34):13921-13926.

74. Préfontaine D, et al. Increased IL-33 expression by epithelial cells in bronchial asthma. J Allergy Clin Immunol. 2010;125(3):752-754.

75. Préfontaine $\mathrm{D}$, et al. Increased expression of IL-33 in severe asthma: evidence of expression by airway smooth muscle cells. JImmunol. 2009;183(8):5094-5103.

76. Kearley J, et al. Cigarette smoke silences innate lymphoid cell function and facilitates an exacerbated type I interleukin-33-dependent response to infection. Immunity. 2015;42(3):566-579.

77. Hardman CS, Panova V, McKenzie AN. IL-33 citrine reporter mice reveal the temporal and spatial expression of IL-33 during allergic lung inflammation. Eur JImmunol. 2013;43(2):488-498.

78. Takeda $\mathrm{T}$, et al. Platelets constitutively express IL-33 protein and modulate eosinophilic airway inflammation. J Allergy Clin Immunol. 2016;138(5):1395-1403.e6.

79. Cayrol C, Girard JP. Interleukin-33 (IL-33): a nuclear cytokine from the IL-1 family. Immunol Rev. 2018;281(1):154-168.

80. Shimokawa C, et al. Mast cells are crucial for induction of group 2 innate lymphoid cells and clearance of helminth infections. Immunity. 2017;46(5):863-874.e4.

81. Russi AE, Ebel ME, Yang Y, Brown MA Male-specific IL-33 expression regulates sexdimorphic EAE susceptibility. Proc Natl Acad Sci U S A. 2018;115(7):E1520-E1529.

82. Ali S, et al. The dual function cytokine IL-33 interacts with the transcription factor NF- $\mathrm{\kappa B}$ to dampen NF-kB-stimulated gene transcription. JImmunol. 2011;187(4):1609-1616.

83. Travers J, et al. Chromatin regulates IL-33 release and extracellular cytokine activity. Nat Commun. 2018;9(1):3244.

84. Bessa J, et al. Altered subcellular localization of IL-33 leads to non-resolving lethal inflammation. JAutoimmun. 2014;55:33-41.

85. Kouzaki H, Iijima K, Kobayashi T, O'Grady SM, Kita $\mathrm{H}$. The danger signal, extracellular ATP, is a sensor for an airborne allergen and triggers IL-33 release and innate Th2-type responses. J Immunol. 2011;186(7):4375-4387.

86. Kakkar R, Hei H, Dobner S, Lee RT. Interleukin 33 as a mechanically responsive cytokine secreted by living cells. J Biol Chem. 2012;287(9):6941-6948.

87. Lefrançais E, et al. IL-33 is processed into mature bioactive forms by neutrophil elastase and cathepsin G. Proc Natl Acad Sci U S A. 2012;109(5):1673-1678.

88. Lefrançais E, et al. Central domain of IL-33 is cleaved by mast cell proteases for potent activation of group-2 innate lymphoid cells. Proc Natl Acad Sci U S A. 2014;111(43):15502-15507.

89. Clancy DM, et al. Extracellular neutrophil proteases are efficient regulators of IL-1, IL-33, and IL-36 cytokine activity but poor effectors of microbial killing. Cell Rep. 2018;22(11):2937-2950.

90. Cayrol C, et al. Environmental allergens induce allergic inflammation through proteolytic maturation of IL-33. Nat Immunol. 2018;19(4):375-385.

91. Cayrol C, Girard JP. The IL-1-like cytokine IL-33 is inactivated after maturation by caspase-1. Proc Natl Acad Sci U S A. 2009;106(22):9021-9026.

92. Lüthi AU, et al. Suppression of interleukin-33 bioactivity through proteolysis by apoptotic caspases. Immunity. 2009;31(1):84-98.

93. Tsuda H, Komine M, Karakawa M, Etoh T, Tominaga S, Ohtsuki M. Novel splice variants of IL-33: differential expression in normal and transformed cells. J Invest Dermatol. 2012;132(11):2661-2664.

94. Hong J, et al. Identification of constitutively active interleukin 33 (IL-33) splice variant. J Biol Chem. 2011;286(22):20078-20086.

95. Gordon ED, et al. Alternative splicing of interleukin-33 and type 2 inflammation in asthma. Proc Natl Acad Sci U S A. 2016;113(31):8765-8770.

96. Pinto SM, et al. A network map of IL-33 signaling pathway. J Cell Commun Signal. 2018;12(3):615-624.

97. Hayakawa H, Hayakawa M, Tominaga SI. Soluble ST2 suppresses the effect of interleukin-33 on lung type 2 innate lymphoid cells. Biochem Biophys Rep. 2016;5:401-407.

98. Hayakawa H, Hayakawa M, Kume A, Tominaga S. Soluble ST 2 blocks interleukin-33 signaling in allergic airway inflammation. J Biol Chem. 2007;282(36):26369-26380.

99. Molofsky AB, Savage AK, Locksley RM. Interleukin-33 in tissue homeostasis, injury, and inflammation. Immunity. 2015;42(6):1005-1019.

100.Gächter T, Moritz DR, Gheyselinck J, Klemenz R. GATA-dependent expression of the interleukin-1 receptor-related T1 gene in mast cells. Mol Cell Biol.1998;18(9):5320-5331.

101.Bonilla WV, et al. The alarmin interleukin-33 drives protective antiviral $\mathrm{CD} 8^{+} \mathrm{T}$ cell responses. Science. 2012;335(6071):984-989.

102. Baumann C, et al. T-bet- and STAT4-dependent IL-33 receptor expression directly promotes antiviral Th1 cell responses. Proc Natl Acad Sci U S A. 2015;112(13):4056-4061.

103. Schiering C, et al. The alarmin IL-33 promotes regulatory T-cell function in the intestine. Nature. 2014;513(7519):564-568.

104.Mjösberg JM, et al. Human IL-25- and IL-33responsive type 2 innate lymphoid cells are defined by expression of CRTH2 and CD161. Nat Immunol. 2011;12(11):1055-1062.

105. Pascual-Reguant A, et al. TH17 cells express ST2 and are controlled by the alarmin IL-33 in the small intestine. Mucosal Immunol. 2017;10(6):1431-1442.

106. Allakhverdi Z, Smith DE, Comeau MR, Delespesse G. Cutting edge: The ST2 ligand IL-33 potently activates and drives maturation of human mast cells. JImmunol. 2007;179(4):2051-2054.

107. Moro K, et al. Innate production of $\mathrm{T}(\mathrm{H}) 2$ cytokines by adipose tissue-associated c-Kit(+)Sca-1(+) lymphoid cells. Nature. 2010;463(7280):540-544.

108.Pecaric-Petkovic T, Didichenko SA, Kaempfer S, Spiegl N, Dahinden CA. Human basophils and eosinophils are the direct target leukocytes of the novel IL-1 family member IL-33. Blood. 2009;113(7):1526-1534.

109. Chen WY, Hong J, Gannon J, Kakkar R, Lee RT. Myocardial pressure overload induces systemic inflammation through endothelial cell IL-33. Proc Natl Acad Sci U S A. 2015;112(23):7249-7254.

110. Boudaud M, Turcotte S, Stankova J, Rola-Pleszczynski M. IL-33 Upregulates cysteinyl 
leukotriene receptor type 1 expression in human peripheral blood $\mathrm{CD} 4^{+} \mathrm{T}$ lymphocytes. J Immunol. 2018;201(9):2787-2798.

111. Liu T, et al. Type 2 cysteinyl leukotriene receptors drive IL-33-dependent type 2 immunopathology and aspirin sensitivity. Jmmunol. 2018;200(3):915-927.

112. Hackett NR, et al. The human airway epithelial basal cell transcriptome. PLoS One. 2011;6(5):e18378.

113. Yagami A, et al. IL-33 mediates inflammatory responses in human lung tissue cells. JImmunol. 2010;185(10):5743-5750.

114. Liu B, et al. IL-33/ST2 signaling excites sensory neurons and mediates itch response in a mouse model of poison ivy contact allergy. Proc Natl Acad Sci U S A. 2016;113(47):E7572-E7579.

115. Halim TYF, et al. Tissue-restricted adaptive type 2 immunity is orchestrated by expression of the costimulatory molecule OX4OL on group 2 innate lymphoid cells. Immunity. 2018;48(6):1195-1207.e6.

116. Schwartz C, et al. ILC2s regulate adaptive Th2 cell functions via PD-L1 checkpoint control. J Exp Med. 2017;214(9):2507-2521.

117. Salimi M, et al. A role for IL-25 and IL-33-driven type-2 innate lymphoid cells in atopic dermatitis. JExp Med. 2013;210(13):2939-2950.

118. Neill DR, et al. Nuocytes represent a new innate effector leukocyte that mediates type-2 immunity. Nature. 2010;464(7293):1367-1370.

119. Stier MT, et al. IL-33 promotes the egress of group 2 innate lymphoid cells from the bone marrow. JExp Med. 2018;215(1):263-281.

120. Halim TY, et al. Group 2 innate lymphoid cells are critical for the initiation of adaptive $\mathrm{T}$ helper 2 cell-mediated allergic lung inflammation. Immunity. 2014;40(3):425-435.

121. Halim TY, et al. Group 2 innate lymphoid cells license dendritic cells to potentiate memory TH2 cell responses. Nat Immunol. 2016;17(1):57-64.

122. Endo $Y$, et al. The interleukin-33-p38 kinase axis confers memory $\mathrm{T}$ helper 2 cell pathogenicity in the airway. Immunity. 2015;42(2):294-308.

123. Morimoto $Y$, et al. Amphiregulin-producing pathogenic memory $\mathrm{T}$ helper 2 cells instruct eosinophils to secrete osteopontin and facilitate airway fibrosis. Immunity. 2018;49(1):134-150.e6.

124. Obata-Ninomiya K, et al. CXCR6 ${ }^{+} \mathrm{ST}^{+}{ }^{+}$memory $\mathrm{T}$ helper 2 cells induced the expression of major basic protein in eosinophils to reduce the fecundity of helminth. Proc Natl Acad Sci U S A. 2018;115(42):E9849-E9858.

125. Minutti CM, et al. Epidermal growth factor receptor expression licenses type- 2 helper $\mathrm{T}$ cells to function in a t cell receptor-independent fashion. Immunity. 2017;47(4):710-722.e6.

126.Van Dyken SJ, et al. A tissue checkpoint regulates type 2 immunity. Nat Immunol. 2016;17(12):1381-1387.

127. Yamamoto T, et al. DUSP10 constrains innate IL-33-mediated cytokine production in ST2hi memory-type pathogenic Th2 cells. Nat Commun. 2018;9(1):4231.

128. Vasanthakumar A, et al. The transcriptional regulators IRF4, BATF and IL-33 orchestrate development and maintenance of adipose tissue-resident regulatory T cells. Nat Immunol.
2015;16(3):276-285.

129.Arpaia $\mathrm{N}$, et al. A distinct function of regulatory T cells in tissue protection. Cell. 2015;162(5):1078-1089.

130. Kuswanto W, et al. Poor repair of skeletal muscle in aging mice reflects a defect in local, interleukin-33-dependent accumulation of regulatory $\mathrm{T}$ cells. Immunity. 2016;44(2):355-367.

131. Morita H, et al. An interleukin-33-mast cell-interleukin-2 axis suppresses papain-induced allergic inflammation by promoting regulatory $\mathrm{T}$ cell numbers. Immunity. 2015;43(1):175-186.

132. de Kleer IM, et al. Perinatal activation of the interleukin-33 pathway promotes type 2 immunity in the developing lung. Immunity. 2016;45(6):1285-1298.

133. Steer CA, Martinez-Gonzalez I, Ghaedi M, Allinger P, Mathä L, Takei F. Group 2 innate lymphoid cell activation in the neonatal lung drives type 2 immunity and allergen sensitization. JAllergy Clin Immunol. 2017;140 (2):593-595.e3.

134. Saluzzo S, et al. First-breath-induced type 2 pathways shape the lung immune environment. Cell Rep. 2017;18(8):1893-1905.

135. Cheon IS, et al. Neonatal hyperoxia promotes asthma-like features through IL-33-dependent ILC2 responses. J Allergy Clin Immunol. 2018;142(4):1100-1112.

136. Cohen $\mathrm{M}$, et al. Lung single-cell signaling interaction map reveals basophil role in macrophage imprinting. Cell. 2018;175(4):1031-1044.e18.

137. Fort MM, et al. IL-25 induces IL-4, IL-5, and IL-13 and $\mathrm{Th} 2$-associated pathologies in vivo. Immunity 2001;15(6):985-995.

138. Lee J, et al. IL-17E, a novel proinflammatory ligand for the IL-17 receptor homolog IL-17Rh1. J Biol Chem. 2001;276(2):1660-1664.

139. Pan G, et al. Forced expression of murine IL-17E induces growth retardation, jaundice, a Th2biased response, and multiorgan inflammation in mice. J Immunol. 2001;167(11):6559-6567.

140. Kim MR, et al. Transgenic overexpression of human IL-17E results in eosinophilia, B-lymphocyte hyperplasia, and altered antibody production. Blood. 2002;100(7):2330-2340.

141. Tamachi T, et al. IL-25 enhances allergic airway inflammation by amplifying a TH2 cell-dependent pathway in mice. JAllergy Clin Immunol. 2006;118(3):606-614.

142. Gregory LG, et al. IL-25 drives remodelling in allergic airways disease induced by house dust mite. Thorax. 2013;68(1):82-90.

143. Shin HW, et al. IL-25 as a novel therapeutic target in nasal polyps of patients with chronic rhinosinusitis. JAllergy Clin Immunol. 2015;135(6):1476-1485.e7.

144. Kang CM, et al. Interleukin-25 and interleukin-13 production by alveolar macrophages in response to particles. Am J Respir Cell Mol Biol. 2005;33(3):290-296.

145. Ikeda K, et al. Mast cells produce interleukin-25 upon Fc epsilon RI-mediated activation. Blood. 2003;101(9):3594-3596.

146.Angkasekwinai P, et al. Interleukin 25 promotes the initiation of proallergic type 2 responses. JExp Med.2007;204(7):1509-1517.

147. Wang YH, et al. IL-25 augments type 2 immune responses by enhancing the expansion and functions of TSLP-DC-activated Th2 memory cells.
JExp Med. 2007;204(8):1837-1847.

148. Corrigan CJ, et al. Allergen-induced expression of IL-25 and IL-25 receptor in atopic asthmatic airways and late-phase cutaneous responses. J Allergy Clin Immunol. 2011;128(1):116-124.

149. Kohanski MA, et al. Solitary chemosensory cells are a primary epithelial source of IL-25 in patients with chronic rhinosinusitis with nasal polyps. JAllergy Clin Immunol. 2018;142(2):460-469.e7.

150. von Moltke J, Ji M, Liang HE, Locksley RM. Tuft-cell-derived IL-25 regulates an intestinal ILC2-epithelial response circuit. Nature. 2016;529(7585):221-225.

151. Howitt MR, et al. Tuft cells, taste-chemosensory cells, orchestrate parasite type 2 immunity in the gut. Science. 2016;351(6279):1329-1333.

152. Gerbe F, et al. Intestinal epithelial tuft cells initiate type 2 mucosal immunity to helminth parasites. Nature. 2016;529(7585):226-230.

153. Schneider C, et al. A metabolite-triggered tuft cell-ILC2 circuit drives small intestinal remodeling. Cell. 2018;174(2):271-284.e14.

154. Nadjsombati MS, et al. Detection of succinate by intestinal tuft cells triggers a type 2 innate immune circuit. Immunity. 2018;49(1):33-41.e7.

155. Goswami S, et al. Divergent functions for airway epithelial matrix metalloproteinase 7 and retinoic acid in experimental asthma. Nat Immunol. 2009;10(5):496-503.

156. Rickel EA, et al. Identification of functional roles for both IL-17RB and IL-17RA in mediating IL-25-induced activities. J Immunol. 2008;181(6):4299-4310.

157. Claudio E, et al. The adaptor protein CIKS/Act1 is essential for IL-25-mediated allergic airway inflammation. J Immunol. 2009;182(3):1617-1630.

158. Swaidani S, et al. The critical role of epithelial-derived Act1 in IL-17- and IL-25-mediated pulmonary inflammation. JImmunol. 2009;182(3):1631-1640.

159. Maezawa $Y$, et al. Involvement of TNF receptor-associated factor 6 in IL-25 receptor signaling. J Immunol. 2006;176(2):1013-1018.

160. Dolgachev V, Petersen BC, Budelsky AL, Berlin AA, Lukacs NW. Pulmonary IL-17E (IL-25) production and IL-17RB + myeloid cell-derived Th2 cytokine production are dependent upon stem cell factor-induced responses during chronic allergic pulmonary disease. JImmunol. 2009;183(9):5705-5715.

161. Corrigan CJ, et al. T-helper cell type 2 (Th2) memory $\mathrm{T}$ cell-potentiating cytokine IL-25 has the potential to promote angiogenesis in asthma. Proc Natl Acad Sci U S A. 2011;108(4):1579-1584

162.Huang Y, et al. IL-25-responsive, lineage-negative KLRG1(hi) cells are multipotential 'inflammatory' type 2 innate lymphoid cells. Nat Immunol.2015;16(2):161-169.

163. Saenz SA, et al. IL25 elicits a multipotent progenitor cell population that promotes $\mathrm{T}(\mathrm{H}) 2$ cytokine responses. Nature. 2010;464(7293):1362-1366.

164. Stock P, Lombardi V, Kohlrautz V, Akbari $\mathrm{O}$. Induction of airway hyperreactivity by IL-25 is dependent on a subset of invariant NKT cells expressing IL-17RB. J Immunol. 2009;182(8):5116-5122.

165. Saenz SA, et al. IL-25 simultaneously elicits distinct populations of innate lymphoid cells and 
multipotent progenitor type 2 (MPPtype2) cells. JExp Med. 2013;210(9):1823-1837.

166. Xu M, Dong C. IL-25 in allergic inflammation. Immunol Rev. 2017;278(1):185-191.

167. Petersen BC, Budelsky AL, Baptist AP, Schaller MA, Lukacs NW. Interleukin-25 induces type 2 cytokine production in a steroid-resistant interleukin-17RB+ myeloid population that exacerbates asthmatic pathology. Nat Med. 2012;18(5):751-758.

168. Angkasekwinai $\mathrm{P}$, Chang $\mathrm{SH}$, Thapa $\mathrm{M}$, Watarai H, Dong C. Regulation of IL-9 expression by IL-25 signaling. Nat Immunol. 2010;11(3):250-256.

169.Zaph C, et al. Commensal-dependent expression of IL-25 regulates the IL-23-IL-17 axis in the intestine. J Exp Med. 2008;205(10):2191-2198.

170.Sawa S, et al. ROR $\gamma \mathrm{t}^{+}$innate lymphoid cells regulate intestinal homeostasis by integrating negative signals from the symbiotic microbiota. Nat Immunol. 2011;12(4):320-326.

171. Xu M, et al. An interleukin-25-mediated autoregulatory circuit in keratinocytes plays a pivotal role in psoriatic skin inflammation. Immunity. 2018;48(4):787-798.e4.

172. Suto H, et al. IL-25 enhances TH17 cell-mediated contact dermatitis by promoting IL- $1 \beta$ production by dermal dendritic cells. JAllergy Clin Immunol. 2018;142(5):1500-1509.e10.

173. Camelo A, et al. IL-33, IL-25, and TSLP induce a distinct phenotypic and activation profile in human type 2 innate lymphoid cells. Blood $A d v$. 2017;1(10):577-589.

174. Ricardo-Gonzalez RR, et al. Tissue signals imprint ILC2 identity with anticipatory function. Nat Immunol. 2018;19(10):1093-1099.

175. Willart MA, et al. Interleukin-1 $\alpha$ controls allergic sensitization to inhaled house dust mite via the epithelial release of GM-CSF and IL-33. J Exp Med. 2012;209(8):1505-1517.

176. Wambre E, et al. A phenotypically and functionally distinct human $\mathrm{TH} 2$ cell subpopulation is associated with allergic disorders. Sci Transl Med. 2017;9(401):eaam9171.

177. Mitson-Salazar A, et al. Hematopoietic prostaglandin $\mathrm{D}$ synthase defines a proeosinophilic pathogenic effector human $\mathrm{T}(\mathrm{H}) 2$ cell subpopulation with enhanced function. J Allergy Clin
Immunol. 2016;137(3):907-918.e9.

178. Ahuja SK, et al. Preservation of epithelial cell barrier function and muted inflammation in resistance to allergic rhinoconjunctivitis from house dust mite challenge. J Allergy Clin Immunol. 2017;139(3):844-854.

179. Hinz D, et al. Lack of allergy to timothy grass pollen is not a passive phenomenon but associated with the allergen-specific modulation of immune reactivity. Clin Exp Allergy. 2016;46(5):705-719.

180. Stämpfli MR, et al. GM-CSF transgene expression in the airway allows aerosolized ovalbumin to induce allergic sensitization in mice. JClin Invest. 1998;102(9):1704-1714.

181. Llop-Guevara A, et al. A GM-CSF/IL-33 pathway facilitates allergic airway responses to sub-threshold house dust mite exposure. PLoS One. 2014;9(2):e88714.

182. Cates EC, et al. Intranasal exposure of mice to house dust mite elicits allergic airway inflammation via a GM-CSF-mediated mechanism. JImmunol. 2004;173(10):6384-6392.

183. Zhou Q, et al. GM-CSF-licensed CD11b lung dendritic cells orchestrate Th2 immunity to Blomia tropicalis. JImmunol. 2014;193(2):496-509.

184.Sheih A, Parks WC, Ziegler SF. GM-CSF produced by the airway epithelium is required for sensitization to cockroach allergen. Mucosal Immunol. 2017;10(3):705-715.

185. Nobs SP, Kayhan M, Kopf M. GM-CSF intrinsically controls eosinophil accumulation in the setting of allergic airway inflammation [published online ahead of print September 20, 2018]. J Allergy Clin Immunol. https://doi.org/10.1016/j.jaci.2018.08.044.

186.Archer NK, et al. Injury, dysbiosis, filaggrin deficiency drive skin inflammation through keratinocyte IL-1 $\alpha$ release [published online ahead of print September 20, 2018]. JAllergy Clin Immunol. https://doi.org/10.1016/j.jaci.2018.08.042.

187. Kearley J, Barker JE, Robinson DS, Lloyd CM. Resolution of airway inflammation and hyperreactivity after in vivo transfer of $\mathrm{CD} 4^{+} \mathrm{CD} 25^{+}$ regulatory $\mathrm{T}$ cells is interleukin 10 dependent. JExp Med. 2005;202(11):1539-1547.

188. Chen W, et al. Conversion of peripheral $\mathrm{CD} 4^{+} \mathrm{CD} 25^{-}$naive $\mathrm{T}$ cells to $\mathrm{CD} 4^{+} \mathrm{CD} 25^{+}$ regulatory T cells by TGF- $\beta$ induction of transcription factor Foxp3. J Exp Med. 2003;198(12):1875-1886.

189. Denney L, et al. Pulmonary epithelial cell-derived cytokine TGF- $\beta 1$ is a critical cofactor for enhanced innate lymphoid cell function. Immunity. 2015;43(5):945-958.

190. Li H, et al. Genetic polymorphisms in transforming growth factor $\beta-1$ (TGFB1) and childhood asthma and atopy. Hum Genet. 2007;121(5):529-538.

191. Corren J, et al. Tezepelumab in adults with uncontrolled asthma. $N$ EnglJ Med. 2017;377(10):936-946.

192.Gauvreau GM, et al. Effects of an anti-TSLP antibody on allergen-induced asthmatic responses. N Engl J Med. 2014;370(22):2102-2110.

193. National Institute of Allergy and Infectious Diseases. Anti-TSLP (AMG 157) Plus Antigen-Specific Immunotherapy for Induction of Tolerance in Individuals With Cat Allergy. NIH website. https:// ClinicalTrials.gov/show/NCT02237196. Published October 1, 2014. Accessed February 27, 2019.

194.Simpson EL, et al. Tezepelumab, an anti-thymic stromal lymphopoietin monoclonal antibody, in the treatment of moderate to severe atopic dermatitis: a randomized phase 2a clinical trial [published online ahead of print December 11, 2018]. JAm Acad Dermatol.https://doi.org/10.1016/j.jaad.2018.11.059.

195. AnaptysBio. Etokimab. AnaptysBio website. https://www.anaptysbio.com/pipeline/ etokimab/. Accessed February 27, 2018.

196. AnaptysBio. A study investigating the efficacy, safety, and PK profile of ANBO2O administered to adult subjects with moderate-to-severe $\mathrm{AD}$ (ATLAS). NIH website. https://ClinicalTrials. gov/show/NCT03533751. Published May 23, 2018. Accessed February 27, 2019.

197. AnaptysBio. Proof of concept study to investigate ANB020 activity in adult patients with severe eosinophilic asthma. NIH website. https://ClinicalTrials.gov/show/NCT03469934. Updated January 31, 2019. Accessed February 27, 2019.

198.AnaptysBio. Placebo-controlled study to investigate ANBO20 activity in adult patients with peanut allergy. NIH website. https://ClinicalTrials. gov/show/NCT02920021. Updated June 26, 2018. Accessed February 27, 2019 